\title{
DIMENSI POLITIS DALAM SASTRA LISAN PADA MASYARAKAT MELAYU DI BANJARAN SUNGAI TANAH DELI
}

\author{
Wan Syaifuddin \\ (Progran Doktor (S-3) Linguistik, Konsentrasi Sastra FIB USU \\ Ketua HISKI Sumatera Utara) \\ E-mail: profwsy@gemail.com
}

\begin{abstract}
Abstrak
Orientasi ruang orang Melayu, pada dasarnya merujuk pada kawasan perairan [sungai dan laut]. Oleh karena itu, masyarakat Melayu dalam studi-studi sosial, selalu disebut sebagai masyarakat aquatik.Peranan buana sungai sebagai konsep kreatif sastra lisan menjadi sendi dalam kehidupan. Nilai dan norma pada karya-karya sastra lisan masyarakat Melayu di banjaran sungai di Tanah Deli Sumatera Utara menjangkau hingga dimensi politis di Tanah Deli, Sumatra Utara memimpin masyarakat yang berbilang etnik. Masalah penelitian ini mengungkapkan bukti keistimewaan dan keagungan peradaban masyarakat dan kesultanannya di Tanah Deli melalui dimensi politis pada sastra lisan masyarakatnya. Tujuan penelitian agar nilai dan norma-norma pada dimensi politis sastra lisan Melayu melekat erat dalam diri dan perilaku masyarakat. Penelitian menggunakan metode kualitatif-diskriptif dengan pendekatan sosio dan resepsi sastra. Penelitian menunjukkan bahwa nilai dan norma dimensi politis yang terkandung dalam sastra lisan pada masyarakat mempunyai hubungan erat dengan perilaku karena berkaitan dengan kepercayaan terhadap adat dan istiadat serta keyakinan masyarakat terhadap Islam. Nilai dan normanya, terlibat dalam pencegahan konflik penguasa dengan masyarakat dan sesama masyarakat.
\end{abstract}

Kata kunci : Sastra lisan, Dimensi Politis, dan Demokrasi

\section{PENDAHULUAN}

\section{Latar Belakang Pemikiran}

Bila dicermati sungai besar yang mengalir di tanah Deli Sumatera Timur berawal dari belahan Barat, yaitu sungai Tamiang, Sungai Wampu, Sungai Deli, Sungai Denai, Sungai Belumai, Sungai Ular, Sungai Padang, Sungai Asahan, dan sungai Billah serta sungai Berombang. Dataran rendah dan tinggi yang merangkai antara masing-masing sungai adalah kawasan rawa, berbukit rendah dan di hulu berbatasan dengan Bukit Barisan. Dataran rendah dan berbukit tempat mengalir sungaisungai ini dibungkus oleh hutan yang luas dengan sifat ekosistemik.

Dilihat dari keragaman hayati kandungan hutan-hutan diantara lembah-lembah sungai ini, amat kaya dan beragam. Yusmar (Syaifuddin, 2017) menyatakan bahwa menempatkannya sebagai satu entitas budaya dengan gemuruh gerakan kebudayaan Melayu di satu sisi, dan eksploitasi bumi berbasis hutan di sisi yang lain telah membuat perubahan- perubahan geomorfologis kosmos pada buana sungai. Ia juga menyatakan bahwa hutandan penyusutan perilaku terhadap ekologinya berdampak pada penyusutan pemahaman makna petuah adat dan istiadat Melayu yang dirupa berbagai genre sastra serta konsep kreatif yang menjadikannya tercitra dalam kearifan-kearifan lokal yang menjadi peneraju hidup dan penuntun berperilaku, sekaligus petuah dalam ikhtiar bagi masyarakatnya.

Sesungguhnya buana sungai menjadi kawasan orientasi ruang, karena di kawasan perairan tersedia ragam fungsi; komunikasi, transportasi, hiburan, pencaharian, sistem pasar, lalu lintas peradaban, dan gerbang untuk berkenalan dengan dunia asing yangjauh.Maka, orang Melayu memilikitabiat dasar 
membangun perkampungan dan kota, termasuk wilayah pusat kekuasaan dalam pola pemukiman yang mengikut garis tebing sungai. Begitu pula halnya dengan kawasan ladang dan huma merujuk pada garis sungai. Musim ikan banyak di laut dan sungai pun merujuk pada peradaran bulan dalam sistem galaksi air. Umpamanya; bulan 'kecil'gelap, penanda ikansedang banyak, karena biota laut termasuk makhluk nocturnal. Sebaliknya, pada masa bulan 'besar', ikan di laut amat langka.

Sejatinya, petuah yang menjadi sandaran dan sendi ikhtiar kehidupan bagi orang Melayu sangat tergantung dari ekosistem buana sungai yang terawat dan terpelihara. Sebaliknya, gerak pembangunan yang tidak linier, sungai-sungai di Sumatera Timur-tanah Deli menjalani masa eksploitasi yang menjenuhkan. Walaupun, kelelahan yang menerpa buana sungai-sungai ini, bakal ikut menggerus mutu atau kualitas petuahdan ikhtiar yang merujuk kepada istiadatserta makna sastra lisan Melayu. Hukum adat dan karya sastra yang selama ini terekam dan tersimpan secara lisan, juga akan mengalami penyusutan makna dan konteksnya.

Makalah ini akan mengutarakan tentang nilai dimensi politis dari sastra lisan yang wujud pada masyarakat di banjaran sungai di Tanah Deli, Sumatera Timur. Secara umum, menurut Setiadi dan Kolip (2013 : 4) berdasarkan upaya penggabungan antar berbagai difinisi yang berbeda mengenai hakikat politik yang dikenal dalam ilmu politik bahwa politik dapat dipahami sebagai proses pembentukan dan pembagian kekuasaan dalam masyarakat antara lain berwujud proses pembuatan keputusan. Dapat juga ia dipahami sebagai proses interaksi antara pihak pihak penguasa dan pihak yang dikuasai, yaitu masyarakat. Manakala perihal nilai dimensi politis, secara khusus Suseno (2016 :17) berpandangan bahwa dalam dimensi-dimensi kesosialan manusia, dimensi politis mencakup lingkaran kelembagaan hukum dan negara serta sistem-sistem nilai dan ideologi-ideologi yang sekaligus memberikan legitimasi kepadanya. Apa yang menjadi ciri khas dimensi politis manusia itu ?. Dimensi politis manusia, adalah dimensi masyarakat sebagai keseluruhan.

\section{Masalah}

Berdasarkan uraian di atas yang bermuara pada kepiawaian lokal dan bersumber dari ketersediaan segala bentuk plasma nutfah buana sungai di dalam sebuah ruang ekologi sungai yang prinsipnya menjadi alat penuntun, tata nilai, dan penyelamat hidup, sekaligus penyelamat lingkungan itu sendiri. Maka, masalah penelitian ini mengungkapkan bagaimanakah nilai dimensi politis dalam sastra lisan masyarakat pada banjaran sungai di Tanah Deli agar kehidupan itu berakal menghadapinya ?

\section{METODE DAN PENDEKATAN}

\section{Metode}

Pada penelitian ini, peneliti bertindak sebagai penganalisis, sekaligus pengamat pada apa yang terjadi pada objek yang diteliti. Kemudian memaparkan nilai dan norma apa yang ada pada teks karya sastra lisan yang melingkupi dimensi politis, sedangkan pada tahapkemudian dipaparkan realitasnya. Oleh karena itu penelitian bersifat diskriftif kualitatif. Data penelitian ini dibatasi pada teks lisan berupa ungkapan atau petuah adat yang digolongkan dalam puisi tradisi Melayu. Kemudian, peneliti sebagai instrumen penelitian adalah melakukan inventarisasi terhadap teks lisandan penafsiran nilai-nilai dimensi politis.

\section{Pendekatan}

Adelbert von Chamissio (1781-1838) meyatakan bahwa kajian-kajian mengenai petuah-petuah adat yang terkemas, seperti berupa ungkapan atau petuah adat serta genre lain, selain memperlihat cerminan akal budi manusia Melayu juga merupakan ekspresi dari kemantapan daya kreativitas dan pemikiran orang-orang Melayu. Francois-Rene Daillie (Yusmar : 2010) juga menyatakan bahwa sejak pertama kali mengenal puisi tradisi Melayu yang berkonsep kreatif buana sungai dan hutan, telah menunjukkan minat yang mendalam tentang keindahannya. Oleh karena, ia menjadi salah satu cara penyampai dan pewarisan nilai dan pengetahuan orang Melayu kepada generasinya. Sejatinya tradisi ekspresif itu, seperti bidal, pepatah, ungkapan adat, gurindam, dan 
syair yang memiliki kekuatan mencerminkan dan membentuk hukum-hukum komunal yang menjadi acuan berperilaku.Sesungguhnya,buana sungai menjadi elemen utama bagi keberadaan Melayu dan adatnya. Tradisi yang meletakkan kearifan pada sungai yang membuat hukum-hukum petuah Melayu selalu merujuk pada ikhtiar menjaga keseimbangan lingkungan.

Suseno (2016:17) berpandangan bahwa Apa yang menjadi ciri khas dimensi politis manusia itu dalam karya sastra, khususnya sastra lisan?. Dimensi politis manusia, adalah dimensi masyarakat sebagai keseluruhan. Jadi yang menjadi ciri khas suatu pendekatan yang disebut politis adalah bahwa pendekatan itu terjadi dalam kerangka acuan yang berorientasi pada masyarakat sebagai keseluruhan. Kemudian sebuah keputusan yang politis pun, apabila diambil dengan memperhatikan kepentingan masyarakat sebagai keseluruhan, sedangkan suatu tindakan atau kebijakan disebut juga politis,apabila menyangkut masyarakat sebagai keseluruhan. Berdasarkan masing-masing uraian tersebut penafsiran/ pemaknaan teks sastra lisan dilakukan.

\section{PEMBAHASAN}

bila duduk, duduk berguru; bila tegak, tegak bertanya; bila merantau mencari ilmu; bila berjalan mencari teladan," bila berkayuh mencaricontoh; bila ke darat mencari ibarat; bila ke laut mencari yang patut'; bila ke tengah mencari yang semenggah; bila ke tepi mencari yang berbudi, bila ke hulu mencari yang tahu".

Masing-masing karya sastra lisan yang berbentuk ungkapan atau petuah adat yang digolongkan dalam puisi tradisi Melayu di atas, hidup dan berkembang secara lisan dimasyarakat yang berada pada banjaran sungai di Tanah Deli Sumatera Timur. Ia juga kerap dikaitkan oleh masyarakat terhadap pembicaraan tentang kekuasaan dan siasyah dalam masyarakat.

\section{Dimensi Awal yang Estetis}

Memahami ungkapan atau petuah-petuah adat tersebut menunjukkan bahwa makna yang menjadi bagian dari tradisi ekspresif Masyarakat Melayu itu, membentuk hukum keseimbangan alam dan keseimbangan hidup antara sesama manusia, masyarakat, dan penguasa. Ihwal konvensi sosial di dalam komunitas Melayu, sebagaimana tercermin dari bagian buana sungai adalah yang memiliki faedah untuk pengendali atau peneraju dalam kehidupan yang ia tersedia di hutan rimba buana sungai-sungai Melayu. Konsep petuah dari ungkapan itu dalam seluruh alam atau sebagai buana sungai Melayu ternyata luas, mencakup segala aspek kehidupan kepercayaan, hubungan sosial, perundangan, dan bernegara serta berbangsa.

Oleh karena itu, melalui pilihan kata-katanya pun menunjukkan bahwa fungsi makna dari petuah adat atau ungkapan dalam kehidupan adalah seperangkat prinsip dasar yang diperlukan untuk mengatur kehidupan demi menuju pada sebuah kerukunan dan keserasian hidup. Untuk itu, maknanya diharapkan agar setiap anggota masyarakat mematuhi segala bentuk aturan bersama yang selanjutnya dikenal sebagai konvensi yang berasal dari sistem nilai yang diatur dalam adat untuk masyarakatnya. Termasuk perilaku yang arif dari masyarakat dalam membangun dan aktivitasnya. , "bila berkayuh mencari contoh; bila ke darat mencari ibarat; bila ke laut mencari yang patut

Maka, secara khusus guna menjaga keasrian, keaslian dan merawat segala jenis ekosistem buana sungai, sesungguhnya melibatkan tokohtokoh yang terkait dengan adat. Sejalan dengan pentingnya posisi para tokoh itu di kalangan masyarakat, ia telah membentuk pola perilaku dan konvensi yang harus juga menjaga keselarasan alam dan lingkungannya. Umpamanya dalam membangun, seperti pembangunan perumahan atau rumah kediaman juga untuk komersial harus bertumpu dan berpaksi pada kaidah petuah adat yang menekankan pentingnya keseimbangan dan tidak memusnah hutan dan tanah dengan makhluk yang hidup didalamnya, ia menjadi pertimbangan utama. Ia manifestasi cara pandang: "adat berumah tak merusak tanah dan sungai ". 


\section{Dimensi Konflik dan Politis}

Secara umum masing masing ungkapan yang bercerita tentang keberadaan, wujudnya potensi dan keberagaman masyarakat di Tanah Deli Sumatera Timur yang teksnya dikemas sedemikian rupa dengan memahami pemikiran Baumgarten (Kartini, 2009) tentang estetika/filsafat keindahan, isi teks lisan ungkapan tidak tidak hanya melingkupi ranah estetika sastra dan budaya, tetapi menjangkau hingga dimensi politik masyarakat Melayu. Oleh karena itu, maknanya mengurai beberapa siasat dan ikhtiar masyarakatnya dan penguasa Melayu di Tanah Deli, dalam berhadapan dengan masyarakatnya yang berbilang etnik.

Hal ini menunjukkan sejalan dengan pandangan Setiadi dan Kolip yang menyatakan bahwa dalam karya-karya sastra, konflik dan integrasi dipahami sebagai gejala sosial yang serba hadir dalam kehidupan sosial, sehingga konflik bersifat inheren. Artinya, konflik akan senantiasa ada dalam setiap ruang dan waktu. Mereka juga menyatakan bahwa dalam karya dimana saja dan kapan saja selama kehidupan sosial masih ada, maka konflik dan integrasi akan selalu menyertainya. Oleh karena itu, dalam padangan ilmu sosial pun, masyarakat dilihat sebagai arena konfik (pertentangan) dan arena integrasi yang akan senantiasa ada sejalan dengan perjalanan kehidupan sosial itu sendiri. Sementara itu, hal-hal yang mendorong timbulnya konflik dan integrasi adalah adanya persamaan dan perbedaan kepentingan sosial. Bahkan dalam setiap kehidupan sosial tidak ada satu pun manusia yang memiliki unsur-unsur kesamaan keinginan, tujuan hidup, ideologi, dan pandangan satu sama lainnya.

Persamaan dan perbedaan tersebut tercermin dalam bentuk deferensiasi antar kelompok yang di dasarkan pada unsur etnis, kepentingan, juga beberapa kemauan, kehendak, dan tujuan. Dari setiap konflik tersebut ada beberapa diantaranya yang dapat diselesaikan, akan tetapi ada juga beberapa diantaranya yang tidak dapat diselesaikan sehingga menimbulkan aksi kekerasan. Kekerasan merupakan gejala dimana gejala yang menyebabkan timbulnya konflik tidak dapat teratasi sehingga menimbulkan kekerasan dari model kekerasan yang terkecil hingga peperangan.

Hadiluwih (2008) dalam penelitiannya tentang KonflikEtnik di Indonesia: Satu Kajian Kes di Bandaranya Medan/Tanah Deli juga menemukan bahwa masyarakat di Tanah Deli terdiridari keturunan, bangsa, etnik, ras maupun agama serta golongan yang berbeda- beda. Perbedaan di Tanah Deli Sumatera Timurini sesungguhnya tidak senantiasa terjadinya konflik, namun perbedaan bisa menjadi sumber laten bagi cultural politik yangbesar kemungkinan awal pada pertembungan antar etnik.

Lebih jauh Sumanindio (2008) menyatakan pada umumnya yang mungkin menjadi sumber konflik di Tanah Deli ada dua macam. Pertama, sumber konflik yang bersifat vertikal, sedangkan yang kedua bersifat horizontal. Secara sosio-politik kedua-dua sumber konflik tersebut bisa digunakan sebagai alat analisis untuk melihat kekerasan dan pertelingkahan atau konflik. Manakala konflik horizontal merentang bermacam alasan yang bisa memicunya. Mulai dari tindak kekerasan, ketaksamarataan, kekejaman, bahkan pembersihan melalui pengabaian hak-hak suatu etnik.

Menganalisis satu demi satu makna petuah adat atau ungkapan tersebut, menunjukkan bahwa makna isi teksnya adalah hasil kristalisasi yang berakar pada fenomena yang ada pada sosial masyarakat dan adat-istiadatnya, bahkan syariat Islam yang di Tanah Deli Sumatera Timur. Mencerminkan bahwa makna dan petuah adat itu tumbuh sebagai pohon rindang yang mengayomi masyarakat Melayu di Tanah Deli. Keadaan ini mengikut filsafat Comte (Tabrani, 1986), makna teks ungkapan dan manusia Melayu adalah suatu keakraban yang hidup sepanjang zaman. Sementara nilai-nilai di dalam teksnya membangun kreatifitas sehingga ia bukan merupakan suatu karya kreatifdogmatis. Dalam Teks ungkapan diungkapkan; "bila ke tepi mencari yang berbudi,bila ke hulu mencari yang tahu".

Walaupun masing-masing teks petuah atau ungkapan adat itu tidak dikemas, dalam peristiwa peperangan dan perjuangan hidup, seperti fiksi, namun bila disimak secara cermat dan teliti, ia dapat ditafsirkan, diantaranya mengungkap 
pandangan dan anggapan yang dilontarkan kepada masyarakatnya di tanah Deli agar menjaga keserasian antar sesama masyarakat walaupun berbeda-beda demi keharmonisan. Daud (2005) menyatakan; rangka isi petuah adat Melayu ada kesamaan dengan isi buku Fenomena Melayu (Mahatir Mohammad, 1985), hanya saja ihktiar dalam teksnya diutarakan lebih bersifat imajinatif Dalam penyampaiannya ia dibingkai dengan genre yang akrab dengan masyarakat Melayu, yaitu petuah adat atau ungkapan.

Selain itu, berdasarkan uraian keberadaan makna teks ungkapan dan konflik di atas menunjukkan wujud dimensi bahwa manusia dan masyarakat yang berbudaya dan terdidik serta berbudi pekerti dalam teksnya. Oleh karena, pada hakikatnya manusia yang berbudaya, terdidik, dan berbudi pekerti merupakan bekal dirinya untuk menatap kehidupan pada masa hadapan. Maka, isi teks petuah atau ungkapan adat dapat dikatakan sebagai impian kolektif- masyarakatnya, tentu dapat pulaia sebagai pelerai konflik masyarakat di Tanah Deli.

\section{PENUTUP}

Berdasarkan pemahaman makna teks itu, menunjukkan bahwa pengalaman masyarakat Melayu, khusus yang berada pada banjaran sungai di Tanah Deli Sumatera Timur berinteraksi dengan puak/etnik dan bangsa yang beragam. Dalam berinteraksi masyarakat Melayu di Tanah Deli telah mendapat tantangan, bahkan tekanantekanan dari keadaan itu, tetapi karena keteguhan jiwa masyarakat Melayu kepada budaya dan adatistiadatnya sehingga mampu diatasi.

Kemudian dari sisi manfaatnya bagi masyarakat dan penguasa Melayu pula, menunjukkan bahwamasyarakat untuk bersiasat dan berikhtiar. Bahkan, menjadi kearifan dalam menerima dan mengatur keberagaman di masyarakatnya, sekaligus menjadi kearifan bagi masyarakat/ penguasanya. Kesemuanya ini, tentu demi memperkukuh kewibawaan marwah dan martabat masyarakat. Tidak hanya itu saja, yang lebih penting siasat dan ikhtiar ini menjadikan masyarakat dan sistem kekuasaan tradisi Melayu di Tanah Deli Sumatera Timur lebih agung daripada yang lain. Keadaan inilah dalam pandangan Alexander Gottlieb Baumgarten dapat dikatakan sebagai kekuatan dimensi politis estetika teks atau sastra lisan berupa ungkapan dalam masyarakat Melayu di wilyah banjaran sungai.

Akhirnya membaca dan memahami serta memaknai makna petuah adat atau ungkapan sebagai estetika teksnya sebagaimana dihuraikan di atas, dapat dimaknai bahwa khalayaknya diarahkan untuk mencari faedah dari pesanpesannya. Dalam konteks kekinian, apalagi menjelang pesta demokrasi dapat menghayati dan mengapresiasi estetika Melayu, khususnya perihal kebertautan dan rasa sepenanggungan sesama masyarakat Melayu. Walaupun pandangan, anggapan, dan siasat ini dikemas bersifat sastra, namun pada konteks pendekatan esetetika sastra, setiap peristiwa mempunyai kebajikan bagi kehidupan dimana dan kapan saja. Kiranya, jiwa manusia Melayu di Tanah Deli Sumatera Timur yang ekspresif akan lebih subur, apabila mampu melogikan perasaannya baik di ranah budaya maupun politik.

\section{DAFTAR PUSTAKA}

Agger, Ben. 2006. Teori Sosial Kritis Kritik, Penerapan, dan Implikasinya, Yogyakarta : Kreasi Wacana.

Barthes, Roland. 2010, Membedah Mitos-Mitos Budaya Massa, Semiotika atau Sosiologi Tanda, Simbol, dan Refresentasi. Yogyakarta: Jalasutra

Budiarjo, Prof.Miriam. 2008. Dasar-Dasar Ilmu Politik. Jakarta: Kompas Gramedia.

Dahlan, Ahmad. 2015. Sejarah Melayu. Jakarta : Kepustakaan Populer Gramedia.

Endraswara, Suwardi. 2009. Metode Penelitian Psikologi sastra, Teori, Langkah, dan Penerapannya. Yogyakarta: Fak. Bahasa dan Seni Universitas Negeri Yogyakarta.

Haji Salleh, Muhammad. 2000. Puitika Sastra Melayu. Kuala Lumpur :Dewan Bahasa Dan Pustaka 
Hadilewih, Sumandiyo, 2008. Konflik Etnik di Indonesia Satu KajianKes di Bandaraya Medan/Tanah Deli. Medan: USU Press.

Hasan, Muhammad Yusof 2004, Pembinaan Paradigma Pemikiran Peradaban Melayu. Kuala Lumpur: Universiti Pendidikan Sultan Idris.

Kartini, Parmono, 2009. Horizon Estetika. Yogyakarta : Badan Penerbit Filsafat UGM \& Lima.

Kutha Ratna, Nyoman. 2004. Teori, Metode, Dan Teknik Penelitian Sastra Dari Strukturalisme hingga Postrukturalime Perspektif Wacana Naratif. Yogyakarta : Pustaka Pelajar
Rahyono, FX, 2009. Kearifan Budaya Dalam Kata, Jakarta:Wedatama Widta Sastra.

Setiadi, Elly M. Dan Kolip Usman. 2013. Pengantar Sosiologi Politik.Jakarta: KharismaPutera Utama.

Syaifuddin, Wan. 2016. Pemikiran Kreatif dan Sastra Melayu Tradisi. Yogyakarta :Penerbit Gading.

Syaifuddin, Wan, Dkk. 2008. Taat Ajar dan Taat Hukum Orang Melayu. Medan: USU Press.

Suseno, Franz Magnis. 2016. Etika Politik PrinsipPrinsip Dasar Moral Kenegaraan Modern. Jakarta : Pustaka Gramedia. 